\title{
Does the Internet Promote Green Total Factor Productivity? Empirical Evidence from China
}

\author{
Zhe Bao, Xiaoliang Zhou, Guanghao Li* \\ School of Economics and Management, Fuzhou University, Fuzhou, China
}

Received: 6 June 2021

Accepted: 30 August 2021

\begin{abstract}
Green development is an inherent requirement for effectively responding to severe resource and environmental problems and adapting to major economic and social problems. Based on the panel data of 272 prefecture-level cities in China from 2011 to 2018, this paper takes the next-generation Internet model city policy as a quasi-natural experiment for the first time, and uses the DID model to empirically test the impact and mechanism of the next-generation Internet model city construction on green total factor productivity (GTFP). The results show that the next-generation Internet demonstration city has a significant role in promoting GTFP, and after being rated as a next-generation Internet demonstration city, its GTFP has increased by about $6.3 \%$. This conclusion is still valid after a series of robustness tests, From the mechanism analysis, it is concluded that the next-generation Internet demonstration cities mainly promote GTFP through industrial structure optimization and technological innovation. A further test of heterogeneity shows that the construction of next-generation Internet demonstration cities is more significant in promoting GTFP in large-scale cities and resource-based cities. The research in this article provides a wealth of empirical evidence for the implementation of my country's next-generation Internet model city policies.
\end{abstract}

Keywords: internet city, GTFP, DID model, heterogeneity analysis

\section{Introduction}

The traditional extensive economic growth mode characterized by factor input and economic scale expansion under the guidance of industrial civilization has brought serious environmental problems to China, the special population, resources and environment determine that China must take the road of environment-friendly [1]. Green development provides an important guarantee for realizing the

e-mail: 351666120@qq.com organic coordination of regional economic development and ecological environment protection, and has become an inevitable choice for the coordinated development of economy, society and ecological environment [2]. How to take the social production mode system reform as the foundation, grasp the high-quality economic development in the new era, and then explore the practical path of green development, It is one of the most important academic topics at present. However, the key to realize sustainable development is to deal with the basic contradiction of productivity and production relations, in which production factors play a vital role. With the development of big data, artificial intelligence and information technology, the digital 
economy was born, The vigorous development of the digital economy has made data a new production factor after entrepreneurial talent, technology, and labor, Its technology empowerment not only improves the digital and intelligent level of the industry, but also reduces the market transaction cost and meets the diversified needs of consumers, data has also become a national basic strategic resource, and its own production and operations are also green industries, which contain huge economic benefits and development prospects [3]. In order to further strengthen China's digital construction, in 2013, the National Development and Reform Commission issued the "Notice on Carrying out the Construction of Next Generation Internet Demonstration Cities", point out that in cities with a certain level of digital infrastructure construction, We will first support the construction of a number of demonstration cities with typical digitalization driving functions, give full play to the characteristics of scale, effectiveness, low consumption and greenness of data in the new era, make it a key production factor to promote high-quality economic development. Its overall goal to strengthen policy demonstration city digital infrastructure construction, speed up the Internet data center, business systems, support systems and other infrastructure upgrades, combined with the new digital services such as Internet of things, big data, development characteristic application in key areas, actively cultivate Internet companies, form the digital industry gathering area, existing development model innovation, We will enhance digital security in the region and promote the rapid and healthy development of the Internet in China. Then, the demonstration cities were assessed on the basis of "infrastructure, user coverage, network application, industrial development and security measures". It can be seen that my country has launched a next-generation Internet model city, aimed at promoting the deep integration of Internet and economic and social development, Promote the construction of ecological civilization and form a good pattern of mutual harmony between economic society and ecological governance. So, in the specific implementation process, does the construction of the Internet demonstration city promote green total factor productivity (GTFP)? What is its mechanism of action? Exploring these problems systematically has important theoretical and practical significance for the implementation of the next generation Internet demonstration city construction and green development in China.

\section{Literature Review}

After Boulding (1966) proposed ecological economics and circular economics, green development has become a topic of widespread discussion among scholars. Green total factor productivity (GTFP) incorporates energy consumption and environmental issues into the analysis framework of total factor productivity, which can effectively reflect the sustainability of economic development of energy consumption and environmental issues, and is a proxy indicator of green development [4]. The research on sustainable development at home and abroad mainly focuses on the measurement, path and spatial heterogeneity of GTFP. For example, Pittman et al. (1983) incorporated pollution control costs into the model to measure the GTFP of enterprises [5], Chung et al. (1997) constructed the MalmquistLuenberger index including environment to measure GTFP [6], Chow (2002) and Wu Y et al. (2008) used the production function method to measure industrial GTFP [7, 8], In view of the fact that the measurement error may be completely ignored in the above algorithm, In recent years, academia has taken more in-depth research on GTFP, DEA and SFA are used to calculate the GTFP [9-11]. Research on GTFP path and spatial heterogeneity, mainly from the misallocation of land resources [12], import trade [13], environmental regulation [14, 15], urban sprawl and so on [16]. As for the literature on the relationship between Internet development and green total factor productivity, Lu et al. (2021) believes that the Internet plays a promoting role in the improvement of industrial green total factor production, and that enterprise innovation ability, enterprise cost, optimization of industrial structure and external supervision are all important ways for the Internet to promote GTFP [17]. Wu et al. (2021) used the spatial SDM model, the intermediary effect model and the dynamic threshold model to investigate the impact of the Internet on China's green total-factor energy efficiency and found that the development of the Internet can not only improve the regional green totalfactor energy efficiency, but also has spillovers on the surrounding areas effect [18]. By using the threshold model and fixed effect model, Li et al. (2020) examines the impact of Internet development on regional GTFP and its internal mechanism. He believes that the impact of the Internet on China 's green total factor productivity is nonlinear, and with the continuous improvement of human capital, the impact of the Internet on GTFP has changed from negative to positive [19]. However, there is a lack of relevant literature on the impact of Internet-related policies on GTFP. Cao et al. (2021) used the multi-period DID method to test the impact of national e-commerce demonstration city policy pilot on GTFP. It is believed that e-commerce demonstration city policy promotes the improvement of urban GTFP, and industrial structure upgrading, non-productive cost reduction and green innovation incentive effect are important mechanisms for urban e-commerce policies to promote GTFP [20]. Qiu et al. (2021) used the DID method to evaluate the impact of the national big data comprehensive experimental area on total factor productivity. He believes that the big data comprehensive experimental area has a significant effect on the regional total factor productivity, and this promotion is mainly technology progress played [21]. 
It can be seen that there is a lack of evaluation of GTFP by pilot policies of next-generation Internet model cities at home and abroad. Therefore, based on the quasinatural experiment of next-generation Internet model cities, this paper evaluates the impact of this policy on GTFP.

Compared with the existing literature, the marginal contribution and potential value of this paper may be as follows. On the one hand, the existing research mostly focuses on the Internet as a variable and uses quantitative analysis method to analyze it. In terms of research methods, this paper regards the nextgeneration Internet demonstration city as a quasi-natural experiment, and uses the DID and propensity matching method to evaluate the impact of the next-generation Internet demonstration city on GTFP, and excludes the policies that potentially affect GTFP, providing more reliable empirical evidence for the promotion of GTFP by the next-generation Internet demonstration city. On the other hand, this paper explains the theoretical mechanism of the next generation Internet demonstration city policy to improve GTFP from the perspective of technological progress and industrial structure optimization, which fills the research gap of the policy.

The second part is theoretical analysis and research hypothesis, the third part is the research design, the fourth part is the empirical results and analysis, the fifth part is robustness test, the sixth part is mechanism analysis, the eighth part is heterogeneity analysis.

\section{Theoretical Analysis and Hypothesis Research}

Labor, capital and technological progress are the main factors driving economic growth. However, on the one hand, as China's aging trend is gradually accelerating, the demographic dividend is gradually disappearing, and the shortage of labor supply is becoming more and more obvious, on the other hand, the scope and scale of China's urbanization process are gradually expanding, the constraints of production factors such as land, energy and raw materials needed for industrial production are becoming more and more tense. Therefore, we should explore the main role of technological progress in the process of economic development. As a technological revolution, the Internet has unique advantages in the transmission, acquisition and application of cross-temporal information. It acts on all fields of social production and economic life, and improves the efficiency of economic operation through the network sharing, intensive integration and efficient use of social production factors. The fundamental goal of the next Generation Internet Demonstration city is to improve the digital industrial system, and then through promoting the application and development of Internet technology, to achieve cross-space high-speed dissemination and diffusion of information. Endogenous growth theory attributes the main driving force of economic growth to innovative activities supported by knowledge accumulation [22-24], and the efficiency of computerized production and dissemination plays a vital role in the accumulation of social knowledge. The Internet promotes the processing and integration of information through the spread of information across time and space, so that every economic individual can enjoy the information brought by the Internet, and integrate and process the information. In the process of information sharing, social human capital continues to accumulate. The impact of technological innovation on GTFP has been confirmed by Liu (2016), Qing (2018), Li (2006) and others, technological innovation can promote the upgrading of production technology, energy saving technology and environmental protection technology of enterprises by improving resource utilization and production efficiency, thus alleviating the previous extensive production mode [25-27]. The Internet can also be used as a platform to connect consumers, producers and scientific research institutions through the Internet, which greatly changes the innovation mode in the economy. Compared with the traditional $\mathrm{R} \& \mathrm{D}$, it is difficult for the three to communicate effectively, the Internet provides a platform for innovation, improves the matching efficiency of innovation activities, and constantly strengthens the relationship between producers and external resources, The opportunities of technology cooperation and R\&D cooperation are gradually increasing, which promotes the improvement and promotion of green production technology and pollution control technology, and further promotes the new mode of green development of enterprises [28, 29].

In addition, in order to realize industrialization, China has given priority to the development of heavy industry, which has resulted in the over exploitation of natural resources and serious excessive industrial exhaust emissions, resulting in resource waste, environmental pollution and many other problems. With the slowdown of China's economic growth, the proportion of the tertiary industry has gradually surpassed the secondary industry, and the industrial structure has been optimized. However, too high proportion of tertiary industry will also bring about negative effects such as regional resource mismatch, industrial hollowing out and serious environmental pollution [30]. How to transform the industry to achieve sustainable development has become a hot topic in the industry. Liu et al. (2021) believe that the improvement of productivity is the core of promoting the upgrading of industrial structure, and the application of the Internet has caused differences in the productivity of different industrial sectors. The efficiency of resource allocation and the reshaping of traditional industries have broken the barriers of information uncertainty between enterprises and consumers, and shaped the diversification of consumer demand. It is a green transformation model in which the industrial structure 
is servicing [31]. Based on the above analysis, we propose the following two research hypotheses:

Hypothesis 1: The next generation Internet model city policy will promote GTFP.

Hypothesis 2: The construction of next-generation Internet demonstration cities mainly promotes GTFP through industrial structure optimization and technological innovation.

\section{Research Design}

\section{Empirical Strategy and Model Design}

The construction of the next generation Internet demonstration cities will not only lead to regional differences between the demonstration cities and the non-demonstration cities among the samples, but also lead to the differences before and after the construction of the demonstration cities. Therefore, these two differences have shaped a good quasi-natural experiment environment for this paper. The policy pilot began in 2013, and in the sample range, 22 cities were used as demonstration cities with typical driving effects. We divided the samples into experimental groups and control groups to test the net effect of the next generation Internet demonstration cities on GTFP according to whether the prefecture-level cities were experimental areas. As the national selection of nextgeneration Internet model cities may be consistent with other policy variables and not exogenous, factors affecting GTFP in cities will be considered, and these related factors cannot be completely observed and controlled. Direct use of OLS estimation is bound to have an impact on policy evaluation results. In view of this, this article uses the DID model for identification, and the empirical model is set as follows:

$$
\text { Gper }_{i t}=\alpha_{0}+\beta_{1} \text { Internet_city } y_{i t}+\text { Controls } s_{i t}+\mu_{i t}+\lambda_{i t}+\varepsilon_{i t}
$$

Among them, $i$ represents the city, $t$ represents the time, Gper ${ }_{i t}$ represents the GTFP the city, Inter_city represents the dummy variable of the next-generation Internet city pilot. The value of the city is 1 after it becomes the pilot, and the value is 0 for the rest of the year. Controls $s_{i t}$ represents a series of Control variables, $\mu$ and $\lambda$ are the city fixed effect and the year fixed effect, respectively, and $\varepsilon$ is the random error term.

\section{Variable Setting and Data Source}

1. Dependent variable. The dependent variable in this paper is GTFP. The calculation of GTFP draws on Yu et al. (2019) method and adopts a non-radial and nonangle SBM model [32], in order to solve the defects that the traditional model does not include slack variables and does not consider efficiency evaluation such as undesirable outputs in the inefficiency measurement.
(1) Input index. This paper selects capital, labor and natural resources as input indexes. Capital mainly adopts the data of capital stock, and the calculation of capital stock adopts the perpetual inventory method. As the panel data of prefecture-level cities are adopted, the data are not as perfect as the provincial data, so the base period is 1991 data, and the depreciation rate is $9.6 \%$ [33]. Labor mainly adopts the sum of unit employees and private employees. The input index of natural resources should ideally select the energy consumption of prefecture-level cities. However, in view of the availability of data, the whole society's electricity consumption is adopted as the substitute index of resource input.

(2) Output indicators. The output indicators selected in this paper are mainly expected output and undesired output. Among them, the expected output is expressed by each GDP city, and the GDP deflator of the province where the prefecture-level city is located is deflated to the 2010 constant price. The undesired output is measured by the three industrial wastes, which are mainly represented by industrial waste water emissions, industrial sulfur dioxide emissions, and industrial smoke and dust emissions.

2. Explanatory variables. In this paper, the interaction term (Internet_city) between the grouping dummy variable ( period $_{i}$ ) and the time dummy variable $\left(\right.$ treat $\left._{i t}\right)$ of the next-generation Internet demonstration city is selected as the core explanatory variable. When the city is a next-generation Internet model city, it is assigned a value of 1 . The rest are 0 , and the city is assigned a value of 1 in the year of the pilot project and subsequent years, and the rest is 0 .

3. Control variables. With reference to the research of Li (2021), Cheng et al. (2021) and others [34, 35], the control variables of this article mainly include: the level of economic development (Pergdp), that is, GDP per capita, Human capital level (Cap), that is, the number of students in regular secondary schools, Infrastructure level (Infra), namely construction land area,The degree of environmental regulation (Enviro), namely the rate of solid waste disposal, The degree of green travel (Gretra), that is, the number of urban public buses and trams operated.

4. Policy variables. According to the research of Xiong (2020), Hu (2020), Qiu et al. (2020), the policy variables in this paper mainly include the pilot policy of carbon emission trading (Pilot), that is, if the city belongs to the pilot city of carbon emission trading in $t$ years or later, Pilot $=1$, otherwise, it is 0 , Low carbon city policy (Low), that is, if the city is a low-carbon pilot city in year $t$ and later, $L o w=1$, otherwise 0 ,Big data comprehensive test area policy (Bdata), that is, if the city is a big data comprehensive test demonstration city in 3 years or later, Bdata $=1$, otherwise it is 0 , Urban e-commerce model city policy (Elect), that is, if the city is an e-commerce model city in $t$ years or later, Elect $=1$, otherwise $0[36,37]$. 
Table 1.Variable descriptive statistics.

\begin{tabular}{|c|c|c|c|c|c|c|}
\hline Variable types & Variable & Observations & Mean & S.D. & Min & Max \\
\hline Dependent variable & GTFP & 2176 & 0.6109 & 0.2273 & 0.0488 & 1 \\
\hline Explanatory variables & Internet_city & 2176 & 0.0607 & 0.2388 & 0 & 1 \\
\hline \multirow{5}{*}{ Control variables } & Pergdp & 2174 & 10.7113 & 0.5942 & 8.7729 & 15.6752 \\
\cline { 2 - 8 } & Cap & 2080 & 2.3952 & 2.3594 & -0.4255 & 12.1261 \\
\cline { 2 - 8 } & Infra & 2152 & 4.488 & 0.9169 & -0.6733 & 7.9778 \\
\cline { 2 - 8 } & Enviro & 2162 & 4.2956 & 0.5165 & -1.4271 & 4.6677 \\
\cline { 2 - 8 } & Gretra & 1978 & 6.5389 & 1.1181 & 3.3673 & 13.9015 \\
\hline \multirow{5}{*}{ Policy variables } & Pilot & 2176 & 0.1029 & 0.3039 & 0 & 1 \\
\cline { 2 - 8 } & Low & 2176 & 0.3051 & 0.4606 & 0 & 1 \\
\cline { 2 - 8 } & Bdata & 2176 & 0.079 & 0.2687 & 0 & 1 \\
\hline
\end{tabular}

This paper selects the eight-year balanced panel data of 272 prefecture level cities in China from 2011 to 2018 as the research sample. During the sample period, 22 cities were selected as the next generation Internet demonstration cities. Information on the model cities is mainly obtained through the central government portal website, the National Development and Reform Commission, the Ministry of Industry Information and other websites. The rest of the data mainly comes from the "China City Statistical Yearbook", "China Environmental Statistics Yearbook", "China Regional Economic Statistics Yearbook", CNRDS database, etc. over the years. Table 1 reports the descriptive statistical results of each variable.

\section{Empirical Results and Analysis}

Analysis of Benchmark Regression Results

Based on the DID model and controlling the urban fixed effect and time fixed effect, this paper examines the impact of the next generation Internet demonstration city policy on GTFP. Table 2 (1) reports

Table 2. Benchmark regression results of next-generation Internet demonstration cities and GTFP.

\begin{tabular}{|c|c|c|c|c|c|c|}
\hline & (1) & (2) & (3) & (4) & (5) & (6) \\
\hline Internet_city & $\begin{array}{l}0.0554^{* * *} \\
(-0.2377)\end{array}$ & $\begin{array}{l}0.0554^{* * *} \\
(-0.0238)\end{array}$ & $\begin{array}{l}0.0637^{* * *} \\
(-0.0242)\end{array}$ & $\begin{array}{l}0.0593^{* * *} \\
(-0.0249)\end{array}$ & $\begin{array}{l}0.0592^{* * *} \\
(-0.0248)\end{array}$ & $\begin{array}{l}0.0634^{* * *} \\
(-0.0299)\end{array}$ \\
\hline Pergdp & & $\begin{array}{c}0.0092 \\
(-0.0155) \\
\end{array}$ & $\begin{array}{c}0.0062 \\
(-0.0157)\end{array}$ & $\begin{array}{c}0.0041 \\
(-0.0158)\end{array}$ & $\begin{array}{c}0.0041 \\
(-0.0157) \\
\end{array}$ & $0.0088(0.0161)$ \\
\hline Cap & & & $\begin{array}{c}-0.0033 \\
(-0.0093)\end{array}$ & $\begin{array}{c}-0.0055 \\
(-0.0093)\end{array}$ & $\begin{array}{c}-0.0057 \\
(-0.0093)\end{array}$ & $\begin{array}{c}-0.0051 \\
(-0.0094)\end{array}$ \\
\hline Infra & & & & $\begin{array}{c}0.0079 \\
(-0.0202)\end{array}$ & $\begin{array}{c}0.0071 \\
(-0.0202)\end{array}$ & $0.0059(0.0217)$ \\
\hline Enviro & & & & & $\begin{array}{c}-0.0039 \\
(-0.0095)\end{array}$ & $\begin{array}{c}-0.0046 \\
(-0.0100)\end{array}$ \\
\hline Gretra & & & & & & $\begin{array}{c}-0.0276^{* * *} \\
(-0.0129)\end{array}$ \\
\hline _cons & $\begin{array}{l}0.6572^{* * *} \\
(-0.0079)\end{array}$ & $\begin{array}{l}0.5615^{* * *} \\
(-0.1616)\end{array}$ & $\begin{array}{l}0.6023^{* * *} \\
(-0.1616)\end{array}$ & $\begin{array}{l}0.5973^{* * *} \\
(-0.1802)\end{array}$ & $\begin{array}{l}0.6184^{* * *} \\
(-0.1849)\end{array}$ & $\begin{array}{l}0.7525^{* * *} \\
(-0.1978)\end{array}$ \\
\hline City fixed effects & YES & YES & YES & YES & YES & YES \\
\hline Year fixed effects & YES & YES & YES & YES & YES & YES \\
\hline Observations & 2176 & 2174 & 2078 & 2070 & 2056 & 1895 \\
\hline R-squared & 0.5597 & 0.5606 & 0.568 & 0.5729 & 0.5748 & 0.5796 \\
\hline
\end{tabular}

Note: ${ }^{* * *},{ }^{* *}$ and ${ }^{*}$ indicate significant levels at $1 \%, 5 \%$ and $10 \%$ respectively, and standard errors are reported in parentheses. 
that the estimated coefficient is significantly positive at the $1 \%$ level under the control of only urban fixed effects and time fixed effects. In order to further alleviate the estimation bias caused by the omitted variables, in section (2)-(6)After gradually adding control variables that may affect GTFP in the column, the estimated coefficient is significant at the $1 \%$ level and the coefficient is positive. R-squared rises from 0.5597 to 0.5796 , an increase of $3.5 \%$. Column (1) in Table 2 reports that when Internet_city only controls the fixed effect of city and fixed effect of time, the estimated coefficient is significantly positive at the level of $1 \%$. In order to further alleviate the estimation bias caused by the omission of variables, the control variables that may affect GTFP are gradually added into columns (2)-(6). The estimated coefficient of Internet_city is significant and positive at the level of $1 \%$, and the R-squared increases from 0.5597 to 0.5796 , with an increase of $3.5 \%$. Obviously, the introduction of a series of control variables has a certain effect on alleviating the omitted variables. From the results in column (6), it can be seen that after being selected as a next-generation Internet model city, its GTFP has increased by about $6.3 \%$, indicating that under the premise that other conditions remain unchanged, the GTFP of pilot cities is higher than that of non-pilot cities city.

So far, this article has reason to believe that the next-generation Internet model cities will promote the improvement of the GTFP. Hypothesis 1 has been verified.

\section{Test on Policy Effectiveness}

The prerequisite for the validity of the DID model is that the experimental group and the control group meet the parallel trend assumption before modeling. In the regression of the benchmark model in this article, the parallel trend assumption means that before the implementation of the next-generation Internet model city policy, the GTFP of pilot cities and non-pilot cities are basically the same in terms of time trends, and after the policy is implemented, the experimental group and the control group The breaking of the parallel trend of, indicates that the GTFP of pilot cities has changed compared with non-pilot cities. As shown in Fig. 1, the horizontal axis represents the time point of the policy, the vertical axis represents the urban GTFP, and the dotted line represents the policy implementation year. Fig. 1 shows that the urban GTFP was not significant before 2013, which indicates that before the implementation of the next-generation Internet demonstration policy, the experimental group and the control group had the same changing trend, and there was no significant difference. However, after 2013, urban GTFP is significantly positive, which shows that the implementation of the policy has a positive impact on GTFP, and as time goes by, the effect of the policy becomes stronger and stronger, but it is not long-term.

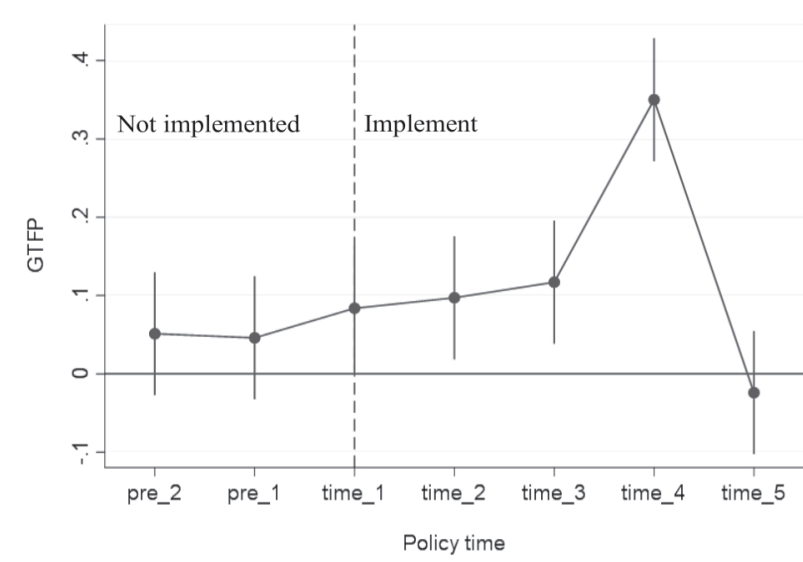

Fig. 1. Time trends before and after policy implementation.

From this, it can be concluded that the parallel trend of the DID model in this paper has passed the test.

\section{Robustness Checks}

\section{Counterfactual Test}

The premise of using DID model is whether the experimental group and the control group are comparable, that is, there is no next-generation Internet model city policy, and the GTFP the cities in the experimental group and the control group will not show significant difference over time. In order to verify this premise, this paper draws on the practice of Shi (2020) and Sun et al. (2020) to advance the time of policy occurrence to 2012 and start implementing, and then carries out the test consistent with the baseline regression $[38,39]$. The results of the counterfactual test are shown in column (1) of Table 3. If the policy is brought forward to 2012, the coefficient of the key interaction item treat $\times$ period in the next-generation Internet model city is not significant. This shows that before the actual implementation year of the policy, the next-generation Internet model cities have no significant impact on the GTFP, which means that the actual policy pilot years can indeed significantly improve the urban GTFP. This also shows that the results of the previous benchmark regression have a certain degree of robustness.

\section{Placebo Test}

Based on the study of Cantoni et al. a placebo test is constructed to determine whether the promotion effect of the next generation Internet demonstration cities on GTFP is caused by other random factors [40]. According to the distribution of the next generation Internet model cities in 272 cities, the processing group was randomly generated and regression was repeated for 1000 times to obtain the estimated coefficients of the policy variables of the next generation Internet 


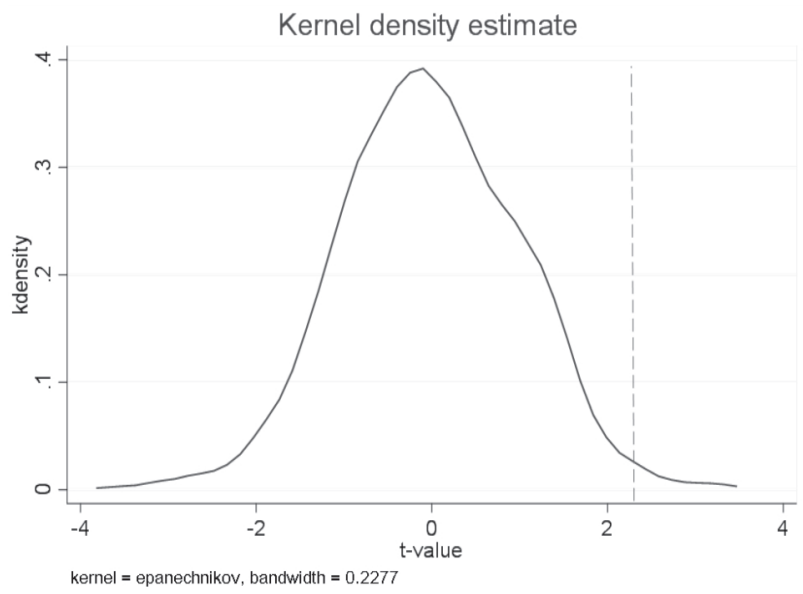

Fig. 2. Placebo test.

model cities in 1000 regressions, and the kernel density map of the distribution of the estimated coefficients was drawn. As shown in Fig. 2, the estimated value of random distribution basically obeies normal distribution around 0 , indicating that the next generation Internet model cities have no significant effect in these 1000 random samples. This also proves that the regression results in this paper are robust to a certain extent.

\section{Instrument Variable Approach}

Considering that the approved Next Generation Internet Demonstration Cities are not entirely exogenous events, the choice of Next Generation Internet Demonstration Cities and urban GTFP may be simultaneously determined, resulting in a causal endogenous relationship between the two. At the same time, there are many factors affecting urban GTFP, and the current control variables are difficult to avoid missing variables. Therefore, in order to solve the possible endogeneity problem, instrumental variables (IV) are adopted to mitigate the endogeneity problem in order to identify the net effect of the next generation Internet model cities on GTFP. The selection of instrumental variables should meet the two requirements of correlation and exogenicity, that is, instrumental variables are correlated with explanatory variables and uncorrelated with explained variables. Learning from Kolko (2012), the urban terrain undulation is used as an instrumental variable for the next-generation Internet model city policy [41]. On the one hand, the instrumental variable satisfies the relevance. The terrain undulation will not only increase the construction cost of network infrastructure, but also affect the network base station. Signals have a negative impact on the operating efficiency of network infrastructure. On the other hand, terrain undulation, as a geographic indicator, will not have an impact on urban GTFP. Therefore, this paper takes the undulation degree of urban terrain as an instrumental variable for the next-generation Internet demonstration city.

From Table 3 (2) and (3) of the regression results of the model, it can be seen that Cragg-Donald Wald F statistics and Kleibergen-Paap rk Wald F statistics are greater than the critical value of 16.38 at the $10 \%$ level, which rejects the original hypothesis that instrumental variables are weak recognition. For the test of the original hypothesis insufficient recognition of instrumental variables, the $\mathrm{P}$ value of LM statistics is 0.000 , which significantly rejects the original hypothesis. To sum up, it shows the effectiveness of selecting urban topographic undulation as an instrumental variable in this paper. At the same time, we found that the core explanatory variable Internet_city is significantly positive at the level of $1 \%$, so the benchmark regression results of this paper have a certain degree of robustness.

Table 3. Counterfactual test and instrument variable approach.

\begin{tabular}{|c|c|c|c|}
\hline & $(1)$ & $(2)$ & $(3)$ \\
\hline Internet_city & $\begin{array}{c}0.0023 \\
(0.0399)\end{array}$ & $\begin{array}{c}1.4215^{* * *} \\
(0.3247)\end{array}$ & $\begin{array}{c}1.4088^{* * *} \\
(0.4742)\end{array}$ \\
\hline cons & $\begin{array}{c}0.7705^{* * *} \\
(-0.1979)\end{array}$ & $\begin{array}{c}0.5247^{* * *} \\
(0.0134)\end{array}$ & $\begin{array}{c}-1.3476^{* * *} \\
(0.5096)\end{array}$ \\
\hline Control variables & YES & NO & $18.531[16.38]$ \\
\hline Cragg-Donald Wald F statistic & - & $31.139[16.38]$ & $21.847[16.38]$ \\
\hline Kleibergen-Paap rk Wald F statistic & - & $60.983[16.38]$ & YES \\
\hline City fixed effects & YES & YES & YES \\
\hline Year fixed effects & YES & YES & 1895 \\
\hline Observations & 1895 & 0.6748 & 0.7127 \\
\hline R-squared & 0.5785 & & 0.648 \\
\hline
\end{tabular}

Note: ${ }^{* * *},{ }^{* *}$ and ${ }^{*}$ indicate significant levels at $1 \%, 5 \%$ and $10 \%$ respectively, and standard errors are reported in parentheses. 


\section{Propensity Score Matching Test}

The traditional DID model may have "selection bias". This article will further use the PSM-DID method for robustness testing. In the use of PSM-DID, Logit regression is carried out on the control variable by whether it is the virtual variable of the next generation Internet demonstration city, and the propensity matching value is obtained. The city with the closest propensity matching value is the pairing city of the next generation Internet demonstration city. However, it should be noted that before PSM-DID processing, the matching effect balance test must be satisfied. This article refers to the research of $\mathrm{Yu}$ (2020), Lu et al. (2019) and others, using control variables instead of covariates, and using kernel matching The method conducts hypothesis testing and finds that the matching covariates are not significant and the absolute value of the standard deviation is less than $20 \%$, indicating that the matching result is valid, and then the matching result is further used to regress the DID model $[42,43]$. The results are shown in Table 4 (1) As shown in the column, the next-generation Internet model city policies have significantly improved the urban GTFP. This shows that the previous benchmark regression results have a certain degree of robustness.

\section{Sensitivity Test}

In this paper, referring to the practice of Liu et al. (2021), the ultra-efficiency DEA model is used to measure the level of urban GTFP, and the measured value is logarithmized to be used as a substitute index for non-radial and non-angular SBM model to measure the level of urban GTFP. With this as a comparison, the robustness of the above benchmark regression results is demonstrated [44]. As shown in Table 4, column (2) is the regression result after controlling for the fixed effect of the city and the fixed effect of time without introducing control variables. The result shows that the next-generation Internet demonstration city has a significant role in promoting the urban GTFP. (3) After the introduction of control variables, the impact of nextgeneration Internet demonstration cities on the urban GTFP is still significantly positively correlated, and R-squared is significantly improved. This also shows that the above benchmark regression results have a certain degree of robustness.

\section{Eliminate Disturbing Policies}

Pilot cities for setting up next-generation Internet demonstrations are generally national or regional central cities, and there are often many simultaneous or superimposed implementations of location-oriented policies based on the national level. In order to exclude the influence of other location-oriented policies, this article controls policy variables that are strongly related to the urban GTFP. Specifically, five policy dummy variables are added to the benchmark regression to examine the impact of the next-generation Internet model cities on the GTFP under the control of other policy interference. Table 4 reports the above regression results. Section (4)-(6) is listed as the estimation result of adding policy variables item by item, and column (7) is the estimation result after adding all the policy variables. It can be found that the next-generation Internet model city policy has an impact on the GTFP of the city when other policies are excluded. The level still has a significant positive promotion effect, which is consistent with the previous benchmark regression results, indicating that the previous benchmark regression has a certain degree of robustness.

Table 4. Other robustness checks.

\begin{tabular}{|c|c|c|c|c|c|c|c|}
\hline & $(1)$ & $(3)$ & $(3)$ & $(4)$ & $(5)$ & $(6)$ & $(7)$ \\
\hline Internet_city & $\begin{array}{c}0.0663^{* *} \\
(0.0396)\end{array}$ & $\begin{array}{c}0.1674^{* * *} \\
(0.0599)\end{array}$ & $\begin{array}{c}0.1475^{* *} \\
(0.0760)\end{array}$ & $\begin{array}{c}0.0635^{* * *} \\
(0.0299)\end{array}$ & $\begin{array}{c}0.0638^{* * *} \\
(0.0308)\end{array}$ & $\begin{array}{c}0.0559^{* *} \\
(0.0308)\end{array}$ & $\begin{array}{c}0.0560^{* *} \\
(0.0308)\end{array}$ \\
\hline Pilot & - & - & - & Control & Control & Control & Control \\
\hline Low & - & - & - & & Control & Control & Control \\
\hline Bdata & - & - & - & & & Control & Control \\
\hline Elect & - & - & - & & & Control \\
\hline cons & $0.9473^{* * *}$ & $-0.8961^{* * *}$ & $-1.3163^{* * *}$ & $0.7528^{* * *}$ & $0.7531^{* * *}$ & $0.7554^{* * *}$ & $0.7634^{* * *}$ \\
$(0.2583)$ & $(0.0200)$ & $(0.5012)$ & $(0.1980)$ & $(0.1982)$ & $(0.1976)$ & Y.1980) \\
\hline Control variables & YES & NO & YES & YES & YES & YES & YES \\
\hline City fixed effects & YES & YES & YES & YES & YES & YES & YES \\
\hline Year fixed effects & YES & YES & YES & YES & YES & YES & YES \\
\hline Observations & 1239 & 2176 & 1895 & 1895 & 1895 & 1895 & 1895 \\
\hline R-squared & 0.5884 & 0.4605 & 0.4981 & 0.5796 & 0.5796 & 0.5822 & 0.5823 \\
\hline
\end{tabular}

Note: ${ }^{* * *},{ }^{* *}$ and ${ }^{*}$ indicate significant levels at $1 \%, 5 \%$ and $10 \%$ respectively, and standard errors are reported in parentheses. 


\section{Mechanism Analysis}

The above research shows that the next-generation Internet demonstration cities have significantly improved the city's GTFP. Then, what is the specific transmission mechanism? In other words, what are the key variables that the next-generation Internet demonstration cities normally influence to increase the city's GTFP? According to the task requirements of the implementation of the next-generation Internet policy, this article will comprehensively examine the specific mechanism of the pilot policy of the next-generation Internet demonstration city to improve the city's GTFP from the industrial structure and technological innovation.

\section{The Test of the Intermediary Effect of Industrial Structure}

Demonstration cities for next-generation Internet may promote urban GTFP through optimization and upgrading of industrial structure. Traditional industries can use the Internet to carry out technological transformation to achieve low-carbon upgrades, and other industries can achieve the process of urban "retreat from two to three" through the optimization of industrial structure, promote the "service-oriented" green transformation, and thereby reduce pollutant emissions. In order to verify this mechanism, Referring to the methods of Gan (2011) and Song et al. (2019), this paper adopts the ratio of tertiary industry to secondary industry (Tech) as the alternative variable of industrial structure optimization $[45,46]$. The regression results are shown in Table 5, where the explained variable in column (1) is industrial structure (Tech), and the explained variable in column (2) is (GTFP). The results show that the coefficient of Internet_city is significantly positive in column (1), which indicates that the policy of next generation Internet model city significantly promotes the optimization of industrial structure. The coefficient of Internet_city is significantly positive in column (2) and decreases relative to the baseline regression result. This indicates that the mediating variable has a partial mediating effect but not a complete mediating effect, that is, the next generation Internet model city policy can promote the improvement of urban GTFP through the optimization and upgrading of industrial structure.

\section{The Examination of the Intermediary Mechanism of Technological Innovation}

Demonstration cities for the next generation of Internet may promote urban GTFP through technological innovation. Internet applications have improved market transparency and provided a zero-distance innovation platform between innovative producers and consumers. Consumers put forward product demands, and producers closely follow market demands, accelerating technological integration and expansion, forming a new round Progressive technological innovation reduces overcapacity and waste of resources in the production process, thereby promoting urban GTFP. In order to verify the mechanism of action, this article draws on the practice of $\mathrm{Lu}$ (2021) and uses the number of invention patent applications as a substitute variable for technological innovation [17]. The regression results are shown in Table 5, where the explained variable in column (1) is technological innovation ( Stru), the explained variable in column (2) is (GTFP). The results show that the coefficient of Internet_city is significantly positive in column (1), which indicates that the nextgeneration Internet model city policies have significantly promoted technological innovation, and the coefficient of Internet_city in column (2) is significantly positive and is relative to the benchmark regression result. The decrease indicates that the intermediary variable has played a partial but not complete intermediary effect, that is, the next-generation Internet model city policies can promote the improvement of urban GTFP through technological innovation and upgrading of enterprises.

So far, through the analysis of this chapter, this article has reason to believe that the construction of next-generation Internet demonstration cities mainly promotes GTFP through industrial structure optimization and technological innovation. Hypothesis 2 has been verified.

\section{Heterogeneity Analysis}

\section{Heterogeneity of Urban Scale}

The previous analysis shows that next-generation Internet demonstration cities can significantly promote urban GTFP. Does this promotion exist for cities of different sizes? Based on this consideration, according to the latest standards in the Notice on the Adjustment of City Size Classification Standards issued by the State Council in 2014, urban areas with a total resident population of less than 1 million are classified as small and medium-sized cities, while urban areas with a permanent resident population of more than 1 million are classified as large cities. The regression results are shown in columns (1) and (2) of Table 5. Under the scale of large cities, the impact of next-generation Internet cities on the level of urban GTFP is significantly positive, while under the scale of small cities, nextgeneration Internet cities have The impact of the urban GTFP is not significant. The reason may be that the lack of human capital and capital investment in small cities has led to inefficient use of resources, and the Internet infrastructure cannot play its due effect. Based on the empirical results, this article believes that from the perspective of city scale, compared with small and medium-sized cities, large cities tend to gather higher levels of human capital and high-quality innovative elements and capital through mechanisms such as 
Table 5. Mechanism analysis.

\begin{tabular}{|c|c|c|c|c|}
\hline & (1)Tech & (2)GTFP & (3)Stru & (4)GTFP \\
\hline Internet_city & $\begin{array}{l}8031.765^{* * *} \\
(922.0799)\end{array}$ & $\begin{array}{l}0.0554^{* * *} \\
(0.0307)\end{array}$ & $\begin{array}{l}0.0329^{* *} \\
(0.0522)\end{array}$ & $\begin{array}{l}0.0511^{* * *} \\
(0.0300)\end{array}$ \\
\hline Tech & & $\begin{array}{c}1.0100^{*} \\
(8.0400)\end{array}$ & & \\
\hline Stru & & & & $\begin{array}{l}0.0155^{* *} \\
(0.0142)\end{array}$ \\
\hline _cons & $\begin{array}{l}5811.064^{* * *} \\
(6084.809)\end{array}$ & $\begin{array}{l}0.7466^{* * *} \\
(0.1979)\end{array}$ & $\begin{array}{l}3.4069^{* * *} \\
(0.3455)\end{array}$ & $\begin{array}{c}0.8075^{* * *} \\
(0.2042)\end{array}$ \\
\hline Control variables & YES & YES & YES & YES \\
\hline City fixed effects & YES & YES & YES & YES \\
\hline Year fixed effects & YES & YES & YES & YES \\
\hline Observations & 1895 & 1895 & 1895 & 1895 \\
\hline R-squared & 0.1608 & 0.5800 & 0.4115 & 0.5812 \\
\hline
\end{tabular}

Note: ${ }^{* * *},{ }^{* *}$ and ${ }^{*}$ indicate significant levels at $1 \%, 5 \%$ and $10 \%$ respectively, and standard errors are reported in parentheses.

sharing effects and learning effects. Which is conducive to the upgrade and application of energy-saving and emission-reduction technologies, which in turn improves energy utilization efficiency, reduces pollutant emissions, and is more conducive to the improvement of GTFP [47].

\section{The Heterogeneity of Urban Resource Endowments}

Since the development differences between regions are not only reflected in the economic development, but also in resource endowments, the impact of the next-generation Internet model city policies on the urban GTFP may be different in cities with different resource endowments. The regression results are shown in columns (3) and (4) of Table 5. In resourcebased cities and non resource-based cities, the next generation Internet policy significantly promotes the urban GTFP, and the effect of resource-based cities is more significant than that of non resource-based cities. The possible reason is that the secondary industry of resource-based cities accounts for a relatively high proportion of the economy, and the proportion of secondary industry negatively affects the level of green economic growth in the region. This performance is called the "resource curse." [48]. However, on the one hand, Internet demonstration cities have improved the efficiency of resource allocation through technological innovations related to energy conservation and emission reduction, thereby promoting GTFP in cities, on the other hand, the development of Internet demonstration cities has promoted the optimization and upgrading of the employment structure and achieved High-quality employment makes resource-based cities get rid of resource dependence. Based on the above empirical research, this article believes that the next-generation Internet model city policy can provide new ideas for my country's resource-based cities to crack the "resource curse".

Table 6. Heterogeneity analysis.

\begin{tabular}{|c|c|c|c|c|}
\hline & $(1)$ & $(2)$ & $(3)$ & $(4)$ \\
\hline Internet_city & $0.0677^{* * *}$ & -0.0173 & $0.0573^{* *}$ & $0.0065^{*}$ \\
$(0.0308)$ & $(0.1033)$ & $(0.0320)$ & $\begin{array}{c}0.1044) \\
(0.4094 \\
(0.2717)\end{array}$ \\
\hline cons & $0.8551^{* * *}$ & $(1.4448)$ & YES & YES \\
\hline Control variables & YES & YES & YES & YES \\
\hline City fixed effects & YES & YES & YES & YES \\
\hline Year fixed effects & YES & YES & 1149 & 746 \\
\hline Observations & 1824 & 71 & 0.5804 & 0.5976 \\
\hline R-squared & 0.5904 & 0.6659 & & \\
\hline
\end{tabular}

Note: ${ }^{* * *},{ }^{* *}$ and ${ }^{*}$ indicate significant levels at $1 \%, 5 \%$ and $10 \%$ respectively, and standard errors are reported in parentheses. 


\section{Conclusions and Policy Recommendations}

\section{Conclusions}

This paper adopts the panel data of 272 prefecturelevel cities in China from 2011 to 2018, and draws the following conclusions based on the impact of the quasinatural experiment of the next generation Internet demonstration city on GTFP: First, as far as the whole country is concerned, the next generation Internet model city has a significant promoting effect on the GTFP, and its GTFP increases by about $6.3 \%$ after being named as the next generation Internet model city. This conclusion remained true after a series of robustness tests, such as placebo test, counterfactual test, PSM-DID test, instrumental variable estimation, changing explained variables, and eliminating policy interference. Second, the mechanism analysis shows that the next generation of Internet model cities mainly promote GTFP through industrial structure optimization and upgrading and technological innovation. Third, the promotion effect of the construction of the next generation Internet model cities on GTFP is more significant in large-scale cities and resource-based cities.

\section{Policy Recommendations}

Based on the above conclusions, this article draws the following policy implications: First, it should be based on next-generation Internet demonstration cities, accelerate the deep integration of the Internet and traditional industries, and promote the transformation of traditional industries to digital, networked, and intelligent, which is the development of contemporary industries The trend is also an important way to improve the production efficiency of enterprises, reduce waste of resources, and improve quality and efficiency. Second, considering that the optimization of industrial structure and technological innovation are important channels for the next generation of Internet demonstration cities to promote GTFP, the government should take regional technological innovation and industrial structure upgrading as its purpose when promoting subsequent relevant policies. Specifically, in small-scale cities, on the one hand, we should provide innovation guarantee by increasing innovation investment, introducing internet professionals and infrastructure construction, reduce government intervention, build a knowledge sharing platform, promote the free flow of factors and create an innovation atmosphere; On the other hand, we should ensure the rational planning of industrial development in the region, speed up the process of "retreat from two to three" in the city, and promote the transformation and upgrading of regional industrial structure. Thirdly, we should actively promote "Internet + Industry" in resource-based cities, adjust the rational distribution of resources among sectors, improve the efficiency of resource inputs and outputs, accelerate the transformation and upgrading of traditional industries with high energy consumption and high pollution, and form a modern industrial system of energy conservation and emission reduction. Fourth, use of technologies such as big data and the Internet of Things to provide a unified and convenient platform for government supervision and management, and public participation in inquiries and supervision.

\section{Acknowledgments}

This work is supported by the National Social Science Program of China (16AZD002), Major project funding for social science research base in Fujian province social science planning (FJ2020MJD2015), Natural Science Foundation of Ningxia (2021AAC03175).

\section{Conflict of Interest}

The authors declare no conflict of interest.

\section{References}

1. LI D., ZHAO Y. How does Environmental Regulation Effect Green Growth? An Empirical Investigation from China. Polish Journal of Environmental Studies, 30 (2), 2021.

2. SHAN S, GEN S Y, KAMRAN H W. Role of green technology innovation and renewable energy in carbon neutrality: A sustainable investigation from Turkey. Journal of Environmental Management, 249 (113004), 2021.

3. MYEONG S., SHAHZND K. Integrating Data-Based Strategies and Advanced Technologies with Efficient Air Pollution Management in Smart Cities. Sustainability, 13 (13), 2021.

4. BOULDING K.E. The Economics of the Coming Spaceship Earth. New York. 1966.

5. PITTMAN R.W. Multilateral Productivity Comparisons with Undesirable Outputs, Economic Journal, 93 (372), 883, 1983.

6. CHUNG Y.H., FARE R. Productivity and Undesirable Outputs: A Directional Distance Function Approach, Journal of Environmental Management, 51 (3), 229, 1997.

7. CHOW G C. Accounting for Economic Growth in Taiwan and Mainland China: A Comparative Analysis. Journal of Comparative Economics, 30 ( 3), 507, 2002.

8. WU Y. The role of productivity in China's growth: new estimates. China Economic Quarterly, 2008.

9. BAI J.H, JIANG F.X. Research on regional innovation efficiency considering environmental factors: Based on three-stage DEA method .Finance and Trade Economics (010), 104, 2011.

10. FENG J., ZHANG S.Q. Evaluation of China's Provincial Green Total Factor Productivity Based on DEA Method - Analysis on the Difference of Different Models. Journal of Peking University (Natural Science), 53, 151, 2017.

11. ZHU C.L., YUE H.Z. Research on China's economic growth efficiency under environmental constraints. 
Journal of Quantitative and Technical Economics 05, 4, 2011.

12. LI Y.G. Research on the influence mechanism of mismatched land resources on green economic development in China. Nanjing Social Sciences (03), 30, 2021.

13. SHAO J., SHI Z.M., ZHU J.M. Import Trade and the Green Transformation Development of Chinese Cities: A Study Based on Green Total Factor Productivity .International Trade Issues (12), 51, 2020.

14. LI D.S., ZHANG Z.Q. The impact of environmental regulation on urban green total factor productivity. Journal of Beijing Institute of Technology (Social Science Edition), (4), 2020.

15. ZHAO M.L., LIU F.Y. FDI, environmental regulation and urban green total factor productivity in the Yellow River Basin . Economic Geography, 266 (04), 40, 2020.

16. SHAO H.H., XIA H.B. The impact of urban sprawl on green total factor productivity in China. Resources Science, 42 (04), 201, 2020.

17. LU F.C., LIU L.Y., XU Y.B. Research on the influence of Internet development on industrial green total factor productivity. Jiangxi Social Sciences, 41 (01), 39, 2021.

18. WU H.T., HAO Y., REN S. Does internet development improve green total factor energy efficiency? Evidence from China. Energy Policy, 2021.

19. LI T., HAN D., DING Y. How Does the Development of the Internet Affect Green Total Factor Productivity? Evidence From China. IEEE Access, 8, 2164772020.

20. CAO X.G., DENG M., LI H. How does e-commerce city pilot improve green total factor productivity? Evidence from 230 cities in China. Journal of Environmental Management, 289 (7), 112520, 2021.

21. QIU Z.X., ZHOU Y.H. Development of digital economy and regional total factor productivity: An analysis based on national big data comprehensive experimental area .Finance and Economics Research, 1, 2020.

22. BARRO R.J., LEE J.W. Sources of Economic Growth, Carnegie-Rochester Conference Series on Public Policy, 1, 1994

23. BARRO R.J. Economic Growth in a Cross Section of Countries, Quarterly Journal of Economics, 106, 407, 1991.

24. BENHABIB J., and M.M. The Role of Human Capital in Economic Development Evidence: From Aggregate Crosscountry Data, Journal of Monetary Economics, 34, 143, 1994.

25. LIU G., WANG B., ZHANG N. A coin has two sides Whichone is driving China's green TFP growth? Economic Systems, 40 (3), 481, 2016

26. QIAN J., LI J.Y. Does technological progress effectively promote energy conservation and $\mathrm{CO}_{2}$ emission reduction? Science of the Earth Sciences 1, 49, 2018 [In Chinese).

27. LI L.S., ZHOU Y. Can technological advances improve energy efficiency? - The empirical test of China's industrial sector. Management World, 2006

28. SHI D.Q., DING H., WEI P. Can smart city construction reduce environmental pollution? China Industrial Economics, 363 (06), 119, 2018.

29. GUO J.T., LUO P.T. Does the Internet Promote Total Factor Productivity in China? Management World 10, 34, 2016

30. HUANG H.P., LI Y.L., WANG Z.P. Spatial-temporal evolution of urban industrial land ecoefficiency in China based on Super-SBM model and its influencing factors. Acta ecologica Sinica,40 (01), 104, 2020.
31. LIU N.Q., DENG M., CAO X.G. Does the transformation of urban e-commerce promote green and high-quality development? - A quasi-natural experiment based on the construction of national e-commerce demonstration city Finance and Economics Research, 47 (04), 49, 2021.

32. YU Y.Z., YANG X.Z., ZHANG S.H. Research on the spatial-temporal transformation characteristics of China's economic development from high-speed growth to highquality development . Journal of Quantitative \& Technical Economics, 036 (006), 3, 2019.

33. ZHANG J., WU G.Y., ZHANG J.P. Economic Research Journal 10, 35, 2004 [In Chinese].

34. LI J., XIA M.J., WAN Q.M. Research on the influence of specialization and diversification agglomeration of hightech industry on green total factor productivity .Statistics \& Information Forum 04, 42, 2021.

35. CHEN Z.H., JIN W. Does Fiscal Decentralization Affect China's Green Economic Growth? Finance and Trade Research 03, 69, 2021 [In Chinese].

36. XIONG G.Q., SHI D.Q., LI M.N. The impact of lowcarbon city pilot on green technology innovation. Science Research Management 12, 93, 2020 [In Chinese].

37. HU J., HUANG P., SHEN H.T. Can Market Incentive Environmental Regulation Promote Enterprise Technological Innovation? - A natural experiment based on China's carbon emission trading scheme. Financial Research, 475 (01), 175, 2020.

38. SHI D., LI S.L. Emissions trading system and energy use efficiency: A case study of cities at the prefectural level and above. China Industrial Economics, 390 (09), 7, 2020.

39. SUN X.H., ZHANG J.N., ZHEN H. Does "replacing business tax with value-added tax" promote the integrated development of manufacturing and service industry. China Industrial Economics, 389 (08), 7, 2020.

40. CANTONI D., CHEN Y., YANG DY. Curriculum and ideology. Journal of political economy, 125 (2), 338, 2017.

41. KOLKO. Broadband and local growth. Journal of Urban Economics, 71 (1), 100, 2012.

42. YU Y.Z., GUO M.H., HU S. Social environment of trustbreaking and the growth of private enterprises: empirical evidence from urban trust-breaking people .China Industrial Economics, (9), 2020.

43. LU J., WANG E.Z. Impact of new energy demonstration city construction on regional environmental pollution control. Resources Science, 41 (11), 151, 2019 [In Chinese].

44. LIU Y.B., ZHUO C. The impact of green development on poverty reduction: A comparative analysis of contiguous and uncontiguous contiguous poverty-stricken areas in China .Finance and Economics Research 04, 64, 2021.

45. GAN C.H., ZHEN R.G., YU D.F. Influence of industrial structure change on economic growth and fluctuation in China. Economic Study 05, 4, 2011.

46. SONG H., SUN Y.J., CHEN D.K. Evaluation of the effect of government air pollution control on the construction of "low-carbon city" in China .Management World, 035 (006), 95, 2019.

47. CHEN Y., TANG X.H. The synergistic effect of manufacturing agglomeration and city size on urban green total factor productivity .Journal of Southern Economics, 003, 71, 2019

48. LI J.L., XU B. "Curse" or "Gospel" : How does resource abundance affect China's green economic growth? Economic Research Journal 09, 151, 2018 